\title{
Definition and Literature Review on Human Performance Envelope Concept in Aerospace Activity
}

\author{
Victoria RUSU \\ Transilvania University of Brasov, Romania, victoria.rusu@unitbv.ro \\ Gavrilă CALEFARIU \\ Transilvania University of Brasov, Romania, gcalefariu@unitbv.ro
}

\begin{abstract}
Nowadays, the international aviation organizations are focused on safety improvements, using automation systems and applying ergonomic concepts. One of these concepts is Human Performance Envelope, which is used for pilot's performance determination, based on a set of ergonomic factors. The aim of the paper is to give a clear definition of this concept and to establish what the directions for future studies are. For this reason, was done a literature review of what has been done. It was revealed that workload, stress, situation awareness and attention are the most studied factors, while fatigue, vigilance, teamwork, trust and communication are the least studied. Moreover, all the experiments were done on one member of the crew, so the concept was applied on one person, while in reality the action of the team influences the upcoming events, so the concept should be extended on the team. Also, the proposed solutions regard the cockpit improvement using automation systems, thus none of them concerns the psychosocial aspects. So, the concept of Human Performance Envelope offers great possibilities for future ergonomic studies in aviation.
\end{abstract}

\section{Keywords}

ergonomics, pilots, safety, human performance envelope

\section{Introduction}

Nowadays, the technology evolution represents one of the most important factors which influence the ergonomic growth. Artificial Intelligence, robotics and all the automation processes are applied almost in every economic field and of course in aviation. However, somebody needs to be legally responsible for the decisions taken by the machines that is why the humans play one of the crucial roles. In other words, even if the tasks can be automated, people are the ones who are responsible for the efficient and safety system function [1].

The same idea is supported by the captain David Moriarty, who said that according to statistics 70\% of aviation accidents are caused by human error and the other $30 \%$ by the technical failures. But this kind of failures do not happen by hazards. For example, if an aircraft engine breaks, it is because of the incorrect maintenance, or because of some errors in designing or maybe it was used in a wrong way. So, human error is somehow involved in technical failure [2].

In order to verify this hypothesis were analysed the statistical reports made by EUROSTAT (European Statistical Office) [3], EASA (European Union Aviation Safety Agency) [4], ICAO (International Civil Aviation Organization) [5] and SIAA (Civil Aviation Safety Investigation and Analysis Authority) [6].

As a result, the main aviation accidents causes are related to the technical failures and to human error, but all the above-mentioned organizations use a special code for aviation causes, called ADREP. Some examples can be: SCF-NP - System/component malfunction or failure (non-power plant); LOC-I - loss of aircraft control or deviation from the intended flightpath inflight; RE (runway excursion) - An overrun off the runway surface or a veer off. Moreover, all the organizations give statistical data only for a specific territory (UE or just for a country) and for a specific aviation category (ICAO - commercial air transport). These are the reasons why is difficult to have a clear percentage delimitation, but is worth to mention that statistical data confirms that the main causes of aviation accidents are human error and technical failures. 
In order to reduce the number of aviation accidents and to improve safety, international organizations prepare and implement different safety projects, such as European Plan for Aviation Safety (EPAS) or Future Sky Safety (initiated by EREA and funded by the European Union's Horizon 2020). Both of these projects have the same goal, to improve aviation safety through ergonomics.

\section{The Concept of Human Performance Envelope (HPE)}

Even if, physiological measurements on pilots were done in the past decades (even before 1975) [7], the concept of Human Performance Envelope (HPE) brought a new idea: the relationship between multiple ergonomic factors and its influence on the human performance. For the first time, this concept was mentioned in the PhD thesis "Human performance in air traffic control", written by Tamsyn Edwards. According to her literature researches (which included 83 scientific papers) there is a lack of investigations on the relationships between multiple ergonomic factors, as the majority of studies measured one ergonomic factor as an independent variable and the second ergonomic factor as a dependent variable. The 83 articles were selected from different domains: industry, university laboratory, transport, military, medicine, social care and of course aviation. Furthermore, the analysis of the aviation incident reports suggested that the nine ergonomic factors, selected by Eurocontrol experts (stress, workload, fatigue, attention, vigilance, situation awareness (SA), teamwork, communication and trust) contributed to the reported incidents [8]. This means that the nine ergonomic factors can be met in different activity spheres, which include also aviation.

The Human Performance Envelope concept was further developed by the EU-funded (Horizon 2020) transport research programme, "Future Sky Safety", which applied this concept on pilots [9]. Moreover, they have configured the HPE concept as a spider graph (figure 1), in which the corners are represented by the value of each factor, so the human performance could be measured using the graphical illustration. According to the representation and depending on the value of the nine ergonomic factors, the pilot's performance could be optimal, critical or degraded $[7,9]$.

\section{Pilot's performance}

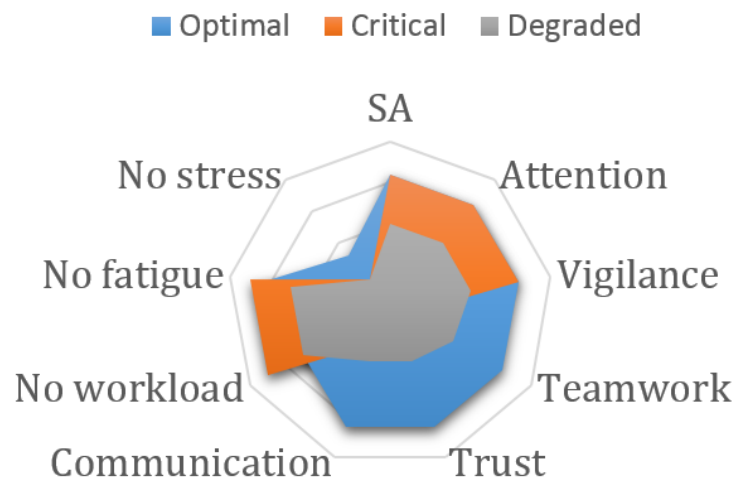

Fig. 1. The graphical representation of HPE concept (adapted after [9])

It is interesting that the selected ergonomic factors which influence the pilot's performance were studied differently across the years, as factors that can be measured easily (workload, stress) were prioritised in research studies [8]. This idea is also supported by the literature review for each factor, presented in the table 1. There are few studies on the Fatigue factor, and the existing ones were focused on the cognitive researches and on the drowsiness. On the other hand, Situation Awareness (SA) is another much studied ergonomic factor, but due to the confusion and overlapping between Attention, Vigilance and Situation Awareness (SA), as the authors and the experts from aerospace field have different visions on this topic, there isn't a clear distinction between these three factors. On the other hand, the relationship between social ergonomic factors like Trust, Communication and Teamwork and their impact on pilot's performance is still unexplored [10]. For a better understanding all the factors will be shortly explained. 
RECENT, Vol. 22, no. 1(63), 2021

Table 1. The summary of the literature review (adapted after [10])

\begin{tabular}{|l|c|c|}
\hline Ergonomic factors & $\begin{array}{c}\text { Pilots references } \\
\text { (number of papers) }\end{array}$ & $\begin{array}{c}\text { General references } \\
\text { (number of papers) }\end{array}$ \\
\hline Mental workload & 12 & 12 \\
\hline Stress & 3 & 6 \\
\hline Mental fatigue & 1 & 11 \\
\hline Situation awareness & 10 & 2 \\
\hline Attention & 0 & 7 \\
\hline Vigilance & 0 & 8 \\
\hline Teamwork & 0 & 2 \\
\hline Communication & 2 & 2 \\
\hline Trust & 0 & 6 \\
\hline
\end{tabular}

\subsection{Workload}

The work tasks which should be accomplished by pilots are related to mental activity, that is why the HPE concepts refers only on mental workload and doesn't take into consideration the physical workload.

The neural communication is limited by the chemical communication on the one hand, and by the speed of electrochemical transmission on the other hand, so the human brain can perform just a limited number of tasks in a specific time. The situations when the tasks exceed the information processing are the same as the situations when a machine's computational capacity is exceeded. This kind of situations are caused, in general, by two factors: (1) multiple tasks that have to be completed within a limited time period or (2) one single complex problem, which can lead to high workload, especially when it should be done in a specified time period [2].

Although, people think that they manage to do simultaneously more tasks, in reality, this ability is quite limited, because human brain is not able to process in the same time more than one information and to offer an adequate response to it. The negative impact of multitasking on the human performance is also demonstrated by an analysis of 19 major airline accidents, which took place in USA, during the period 1990-2001. According to the researches, the cause of the accidents was the crew error and, in particular, the workload issues and the concurrent tasks. All the pilots were highly experienced, but their performance was undercut by the limited brain ability to switch the attention between concurrent tasks and to remember to perform the postponed tasks [11]. This means that the exposure to high workload could be a major threat for aviation safety, but, on the other hand, low workload leads to boredom and to the decrease of vigilance level. This is also a threat for aviation safety, because pilots will not be able to react quickly at an unexpected event. That is why, the level of workload should be monitored, and according to previous studies, the best way to measure mental workload is to combine different methods and techniques as: ECG, EEG, EOG, eye tacking, NASA-TLX and subjective data [10].

\subsection{Stress}

Stress is an ergonomic factor, which is studied in different ways. Modern theories consider that stress is caused by the imbalance between the individual resources and the external or internal demands. If the demands surpass the individual resources, then stress develops, which means that some hormones like cortisol, adrenaline and noradrenaline, are released into the body, due to physiological reactions. These hormones have some advantages for human body, but only when the exposure to stress is for a short period of time, otherwise they can lead to serious health and psychological problems [12].

Moreover, the stress level is different from one profession to another and the Sloan \& Cooper study (1986), suggested that the airline pilot profession take one of the top positions from the ranking with all the professions and their corresponding stress level. On the other hand, captains are considered to be the most affected by stress and not because of their age, but due to the responsibilities they have and the decisions they need to make [13].

In order to cope with the stress, pilots must understand which the stressors are. These ones can be divided in two categories: physical stressors (vibration, noise, turbulence, extreme temperature) and 
psychological stressors (life events, life changes) [14]. This kind of stressors have a negative impact on the pilot's performance (prone to mistakes, attention is diminished, short-term memory is also reduced, visual scanning is more chaotic) [12]. That is why, pilots should be aware of their stress state, in order to find solutions for overpassing it.

\subsection{Fatigue}

Besides stress, fatigue can also negatively influence the pilot's performance and is considered as a cause of accidents. Aviation accidents which had fatigue as one of main causes are: DC-8 crash in Guatemala Bay (1993), Korea Air Flight 801 (1999, 228 deaths), American Airline Flight 1420 (1999, 11 deaths). What concerns incidents, fatigue played a major role in $3.8 \%$ of the total incidents reported to the Aviation Safety Reporting System by pilots [15].

Pilots can face mental fatigue due to functioning at a circadian phase which is non-optimal or due to inadequate sleep or prolonged working hours. The effects of inadequate sleep, which is called sleep deprivation, are manifested as increasing cognitive performance variability and increasing the addiction of compensatory measures (caffeine, motivation). Moreover, sleep deprivation affects the cognitive performance itself, as it becomes worse and even accomplishing a brief task, which involves working memory, attention, and speed of cognitive throughput, becomes a real challenge. Further, sleep loss negatively influences the prefrontal cortex, especially divergent and decision-making skills [16].

As fatigue adversely affects the pilot's performance and, in consequence, the aviation safety, it is necessary to find efficient measurement solutions. One of them can be the Psychomotor Vigilance Test (PVT), which is considered to be an effective method for sleepiness measurements, as a result of good anti-fatigue countermeasures and of sleep restriction [15]. Other methods used for sleepiness monitoring are Electrooculography (EOG), EEG and the combination between them [10].

\subsection{Situation Awareness (SA)}

Federal Aviation Administration give the following definition to Situation Awareness (SA): "The accurate perception and understanding of all the factors and conditions within the four fundamental risk elements that affect safety before, during, and after the flight". The four risk elements mentioned in the definition are: airplane, pilot, external pressures and environment [17]. In other words, situation awareness (SA) represents the interaction between the perceived information from working memory and the long-term memory knowledge, in order to generate an overview of the situation and to make correct decisions for goal achieving [18]. In pilots' case the perception is based on cockpit information regarding the flight display, data-links, engine instruments readout, vision or navigation data and others [17].

On the other hand, according to SA, the pilot should maintain the mental picture formed by the interrelationship of multiple factors (aircraft configuration, weather, terrain proximity, traffic). Under unexpected conditions, the SA concerning one the above-mentioned factors can be lost, which can generate dangerous results: loss of aircraft control, flight into terrain or airspace infringement. There are also external factors (strong winds, air turbulence, heavy icing) which can compromise the SA and can lead to aviation accidents. That is why, pilot's task is to apply cognitive effort for sustaining the mental picture of the flight situation, especially in cases when the capacity of the information processing is exceeded or is at its threshold [17].

All this explained the necessity to assess the situation awareness with self-rating techniques or with inferential techniques. Some of them are: SPAM (Situation Preset Assessment Method), SAGAT (Situation Awareness Global Assessment Technique), SART (Situation Awareness Rating Technique), SASHA (Situation Awareness for SHAPE) and others. Although, there is a wide variety of SA techniques, none of them was fully explored and each of them has been criticised [10].

\subsection{Attention}

Attention represents the mechanism which assigns perceptual and cognitive resources across the controlled processes [15]. On the other hand, attention can be defined as a top-down influence which improves the cognitive responses to the attended objects, situations or visual areas, and which can inhibit the neural response to the not attended information, in this way it does not enter into the 
conscious awareness. In other words, attention is used to hinder and to enhance the perception of the environment [19]. Furthermore, attention can be consciously focused just on one thing or event (for example, pilots search the light during the night) or it can be distributed to some external events (situation when somebody hears his/her name). Thus, attention can be divided in selective and distributed attention [20].

There is a system, which uses EEG and is designed in order to solve the problems regarding to pilot's attentional breakdowns. It is called Communication Scheduler and its functionality is based on the presentation and planning of messages to the user, according to task content, the user's level of mental workload and the message priority. Such kind of system plays an important role in attention monitoring, but the designers must take care, as an inappropriate direction of attention may negatively influence the overall performance [15].

Other researchers investigated the relationship between pilot engagement and attention through some techniques of brain imaging. These techniques provide information about the fatigue level and about the amount of attention paid by pilots to the ongoing events. Moreover, this technology, based on Functional Near Infrared Spectroscopy (fNIRS) collects the information regarding the attentional state over long period of time, and helps to monitor the pilot's attention [21].

\subsection{Vigilance}

Vigilance is considered a state of awareness, which can be low or high, depending on the situation and on the environment. Vigilance is reduced during the periods of fatigue and boredom; thus, it affects directly the Situation Awareness. That is why, pilots should always remain vigilant to the information coming from external events (weather, traffic), from engine systems and from other sources of communication. It is obvious that is hard to maintain a high vigilance state all the time, therefore pilots have to pay attention constantly to the most important data [17].

Some studies use instead of vigilance the notion of sustained attention or passive monitoring, this means that the same phenomenon is described under different names, which makes difficult the understanding and the measuring [2].

\subsection{Teamwork}

In aviation, teamwork is associated with Crew Resource Management (CRM) and in this context, a team is represented by a group of individuals who have a common set of work performance goals and who act with mutual responsibility [22].

It is worth to mention that the concept of teamwork evolved over the last 50 years. Initially it was based on the cockpit management which involved only the crew (First Officer, Captain, Flight Engineer/International Officers) and then it was focused on the connections with other workgroups (flight attendants, dispatchers, gate agents, mechanics, loaders, and others). Besides, there is another very important member, which is called "automation" and is represented by the on-board equipment used for workload reducing and for increasing coordination safety. Moreover, the CRM importance of this member is still rising, as the on-board automated systems are very complex and the crew size is reduced [23].

In every team can exist breakdowns, which can negatively influence the communication between colleagues, situational awareness, decision making and may lead to irritation, frustration, job dissatisfaction, serious incidents or even accidents. That is why is important to monitor the teamwork and to avoid the negative impact on team performance [10].

\subsection{Communication}

Communication may be sometimes misinterpreted, so in aviation oral communication is defined, formalized and regulated. Further, written communication is defined by the Federal Aviation Regulations (FARs) parameters, which include the airworthiness directives or airmen notices. The communication between the crew is based on verbal, written and graphical protocols. However, the misunderstandings still exist and can lead to significant number of aviation accidents. The failure of applying protocols can be one of the accident causes, while other causes may be: the loss of situational 
awareness, the used of wrong information, the failure in building a situational shared model or other reasons [17].

One example of aviation accident caused by poor communication is the Avianca Flight 052, which flew from Medellin (Columbia) to John F. Kennedy International Airport (New York). This 707B Boeing ran out of fuel and crashed over Long Island in 1990. According to NTSB investigations, the main causes of the accident were two failures: (1) the poor flight crew management of the airplane's fuel load, and (2) the poor communication between the crew and the Air Traffic Controllers about the emergency situation, before the full exhaustion of fuel. Other aviation accidents investigated by NTSB and which were caused by communication problems are the United Airlines Flight 173 (1978), United 811 (1990), United 232 (1990) [23].

\subsection{Trust}

Besides teamwork and communication, the crew performance is affected by trust. In aviation, interpersonal trust represents the willingness of maintenance individuals' trust in their co-workers, especially regarding professional tasks and safety. This means that crew members should rely on one another to complete the tasks or commitments. On the other hand, they should protect each other from the unexpected hazard situations [23].

Besides interpersonal trust, pilots should trust their own experience and skills. The trust in yourself is a part of metacognitive reflection and in some specific situations, is recommended the trust in the own judgement, rather than the checking of a problem situation with some external tools [21].

\subsection{Conclusion about factors}

All the nine ergonomic factors are considered psychosocial factors, as they are studied in correspondence with the individual's psychology and with the social environment. Workload, Stress and Fatigue are physiological, as they are responsible for activation of some physiological mechanisms (metabolism, respiratory system, hormonal system, etc.) and there are a lot of measuring possibilities (EEG, ECG, EOG, EMG) for them, in comparison with measurements for the other six factors. Attention, Vigilance and Situation Awareness are cognitive factors as they are associated with the information processing. These three factors create confusion for researchers that is why there are not defined boundaries between them. The last three factors, Teamwork, Communication and Trust are social factors, as they can be analysed only in relationship with others (colleagues, management, and cabin crew) Moreover, they are studied in Crew Resource Management discipline [8, 9, 10].

\section{From Literature Review to Paper Contribution}

\subsection{Proposing the definition}

The HPE is a relatively recent concept (2013) and was briefly studied in E. Tamsyn's PhD thesis and in the "Future Sky Safety" project. The PhD thesis explained the importance of the multifactor model for analysing the Air Traffic Controller's (ATC) performance, while the European project applied this concept on pilots and offered a more detailed explanation.

According to it the HPE is "described as a construct combining a set of interdependent factors and represented with a spider web model. Depending on the value of each factor, the resulting HPE could evolve from fully acceptable to not acceptable. Even though a single factor could have a non-acceptable value, it is assumed that the interaction should enable compensations among factors to be identified, and consequently overall acceptability of HPE to be proven" [10].

The explanation is a complex one, so was proposed a more structured and summarized definition. Human Performance Envelope is an ergonomic concept, based on the analysis of a set of nine interdependent ergonomic factors, which influences the performance of the aviation workers (pilots and Air Traffic Controllers) and is represented by a spider web model, used for the delimitation of the human performance tolerance zone.

\subsection{The boundaries setting}

The HPE concept was further applied in other studies and during the research were found 9 articles on this subject. Introducing the key terms "Human Performance Envelope" on such databases as: Web 
of Science, IEEE, Springer, Scopus, PROQUEST Central and the web search engine Google Scholar, was found out a lot of articles on different subjects. After abstract reading, were downloaded only 34 articles related to pilots or Air Traffic Controller (ATC) and of course to HPE concept. After a more detailed analysis, only 9 articles were selected. These articles applied the HPE concept to pilots or to ATC.

After that, was done a literature analysis (summarized in the table 2), in order to understand what was studied, what ergonomic factors were analyzed and what opportunities are for future studies. In other words, were established the concept boundaries. Just one article isn't in the table, as it offers general information about a European project, "Stress" that will be implemented.

Table 2. Setting the boundaries of what have been already studied

\begin{tabular}{|c|c|c|c|}
\hline $\begin{array}{l}\text { The set of } \\
\text { ergonomic } \\
\text { factors }\end{array}$ & What was studied & Authors & What wasn't studied \\
\hline $\begin{array}{l}\text { 1. SA } \\
\text { 2. Stress } \\
\text { 3. Workload } \\
\quad \text { For pilots }\end{array}$ & $\begin{array}{l}\text { Defining and explaining each } \\
\text { ergonomic factor, the relationship } \\
\text { between them and proposing } \\
\text { recovery measures if the pilot's } \\
\text { performance is out of tolerant } \\
\text { zone. These measures include } \\
\text { innovative human-machine- } \\
\text { interface design, flight crew } \\
\text { monitoring and automation } \\
\text { concepts. Further, determining the } \\
\text { pilot's performance limits using } \\
\text { physiological measurements (e.g., } \\
\text { HR, SDNN, HF, LF, VLF, eye } \\
\text { tracking), in order to apply an } \\
\text { automation support for } \\
\text { performance recovery. Attention } \\
\text { needs other methods of } \\
\text { measurement than stress, } \\
\text { workload or SA. }\end{array}$ & $\begin{array}{l}\text { • Graziani I., } \\
\text { Berberian B., } \\
\text { et al., } 2016 \\
\text { [9] } \\
\text { • Kirwan B., } \\
\text { Wies M., et } \\
\text { al., } 2019 \\
\text { [24] } \\
\text { • Nixon J., } \\
\text { Pilbeam C., } \\
\text { Kirwan B., } \\
\text { 2019 [25] } \\
\text { - Chira A., } \\
\text { Dumitrescu } \\
\text { A., et al., } \\
\text { 2020 [7] }\end{array}$ & $\begin{array}{l}\text { Study extension on the team, } \\
\text { not only on one of the crew } \\
\text { members (captain or first } \\
\text { officer). } \\
\text { The HPE model is more } \\
\text { accurate if there are used } \\
\text { more physiological } \\
\text { parameters and in order to } \\
\text { determine some factors as } \\
\text { vigilance and fatigue are } \\
\text { required longer tests. }\end{array}$ \\
\hline $\begin{array}{l}\text { 1. Workload } \\
\text { 2. Human } \\
\text { Performance } \\
\qquad \text { For ATC }\end{array}$ & $\begin{array}{l}\text { Determining human performance } \\
\text { in different conditions (high } \\
\text { workload and low workload), } \\
\text { using physiological } \\
\text { measurements or some } \\
\text { automation systems for } \\
\text { maintaining the task level. }\end{array}$ & $\begin{array}{l}\text { - Arico P., } \\
\text { Borghini G., } \\
\text { et al., } 2016 \\
\text { [26] } \\
\text { - Nixon J., } \\
\text { Charles R., } \\
2017 \text { [27] }\end{array}$ & $\begin{array}{l}\text { Solutions for performance } \\
\text { rising which will take into } \\
\text { account more workload states } \\
\text { (not just the studied ones). } \\
\text { Modulation methods of the } 10 \\
\text { levels of automation according } \\
\text { to mental workload. }\end{array}$ \\
\hline $\begin{array}{l}\text { 1. Workload } \\
\text { 2. SA } \\
\text { For ATC } \\
\text { and for } \\
\text { pilots }\end{array}$ & $\begin{array}{l}\text { Measuring the level of SA, using } \\
\text { eye tracking physiological } \\
\text { measurements. } \\
\text { Comparing multifactor } \\
\text { relationships (workload, SA) on } \\
\text { the four levels of automation. }\end{array}$ & $\begin{array}{l}\text { - Edwards T., } \\
\text { Homola J., et } \\
\text { al., } 2017 \\
\text { [28] } \\
\text { - Biella M., } \\
\text { Wies M., } \\
2017 \text { [29] }\end{array}$ & $\begin{array}{l}\text { Extending the understanding } \\
\text { of multifactor relationships, by } \\
\text { adding more factors (fatigue, } \\
\text { vigilance, teamwork). } \\
\text { Exploring the interaction } \\
\text { between factors, in order to } \\
\text { create an ecologically valid } \\
\text { understanding of the human } \\
\text { performance in association } \\
\text { with ergonomic factors. }\end{array}$ \\
\hline
\end{tabular}

As can be noticed from the above table, some ergonomic factors, Workload, Stress, SA, are more studied than the others, Fatigue, Teamwork, Communication, Trust, Attention and Vigilance. This 
happened because of the complexity of these factors, as they require more physiological measures, maybe some sociological methods of measuring and much more time for testing. On the other hand, the concept was applied for pilots in a simulation environment (Human-in-the-loop, AVES simulator, complete flight simulator A320, fix simulator Boeing 737) and none of the experiments were done in a real flight. Further, all the tests were applied on one pilot, but in real life flight depends on the decisions taken by both crew members (captain, pilot officer). That is why is important to extend the HPE concept on the team.

In future studies, it is proposed to create a HPE model, which will contain a set of factors, especially the ones that are less studied. Then, will be selected the physiological measures and behavioral markers for each factor, based on the literature review, and they will be tested on six pilots.

Moreover, it is proposed to extend the HPE concept on disabled workers from aviation. These people need a special attention and a good treatment, as they can be good and motivated specialists. Their work and importance are as precious as the others, but there need to be a special infrastructure, which will allow them to do the job.

\section{Conclusion}

Even if aviation is in a continuously developing process, one major cause of accidents is the human error. This is the reason why a lot of international organizations want to reduce the number of aviation accidents by improving aviation safety and worker's conditions. While this is possible if ergonomic concepts or principles are correspondingly applied. Here comes the Human Performance Envelope, which is considered a new paradigm in ergonomics and which contributes to performance determination by using a set of human factors.

The possibility to choose and to combine the proposed nine factors offers a great variety of studying models, measurements and interpretations. On the other hand, there are some ergonomic factors which are studied more (Workload, Stress, SA, Attention) than the rest of the factors. This situation offers a great opportunity for future studies, but these should be based on a deeper literature study concerning the selected factors.

Furthermore, the proposed solutions for error reducing and performance growing are focused on automation improvements and cockpit changes, while there can be some other solutions with a more social and individual accent, like trainings, workshops or social programmes.

Altogether, Human Performance Envelope concept is something new and can be used as a base for different interesting studies, which will lead to pilot's performance grow and, in consequence may be a measure for reducing aviation accidents.

\section{References}

1. Bridger R.S. (2018): Introduction to human factors and ergonomics. CRC Press Taylor \& Francis Group, ISBN 9784987-9594-4, pp. 28-29

2. Moriarty D. (2015): Practical human factors for pilots. Academic Press Elsevier, ISBN 978-0-12-420244-3, p. 4

3. EUROSTAT (2021): Air safety statics in the EU. Available at: https://ec.europa.eu/eurostat/statisticsexplained/index.php/Air safety statistics in the EU\#General aviation. Accessed: 19.04.2021

4. EASA (2020): Annual Safety Review 2020. Catalogue number: TO-AA-20-001-EN-N, ISBN 978-92-9210-222-7, pp. 33-34

5. ICAO (2020): Safety Report. https://www.icao.int/safety/Documents/ICAO SR 2020 final web.pdf. Accessed: 22.04 .2021

6. AIAS (2020): Analiza Accidentelor și Incidentelor Grave din Operațiunile de Aviație Generală (2009-2019). http://www.aias.gov.ro/index.php/ro/publicatii/studii-si-analize-privind-siguranta-zborului/413-analizaaccidentelor-si-incidentelor-grave-din-operatiunile-de-aviatie-generala-2009-2019. Accessed: 23.04.2021. (in Romanian)

7. Chira A.I., Dumitrescu A., Moisoiu C.S., Tanase C.A. (2020): Human Performance Envelope model study using pilot's measured parameters. INCAS BULLETIN, ISSN 2066-8201, Vol. 12, Issue 4/2020, pp. 49-61

8. Edwards T. (2013): Human performance in air traffic control. PhD thesis. University of Nottingham, United Kingdom, p. I-II

9. Graziani I., Berberian B., Kirwan B., Le Blaye P., Napoletano L., Rognin L., Silvagni S. (2016): Development of the Human Performance Envelope Concept for Cockpit HMI Design. HCI-Aero 2016 International Conference on 
Human-Computer Interaction in Aerospace, ISBN 978-1-60558-246-7/09/05, p. 8, Paris, France

10. Silvagni S., Napoletano L., Graziani I., Le Blaye P., Rognin L. (2015): Concept for Human Performance Envelope. Available at: https://www.futuresky-safety.eu/download/. Accessed: 22.04.2021

11. Loukopoulos L.D., Dismukes R.K., Barshi I. (2009): The multitasking myth. Handling complexity in real-world operations. Ashgate Publishing Limited, ISBN 978-0-7546-7382-8, pp. 15-17, 72-73

12. Martinussen M., Hunter D.R. (2010): Aviation psychology and human factors. CRC Press Taylor \& Francis Group, ISBN 978-1-4398-0843-6, pp. 127-134

13. Ebermann H.J., Scheiderer J. (2013): Human factors on flight deck. Safe piloting behaviour in practice. Springer, ISBN 978-3-642-31732-3, pp. 118-120, 170

14. Koonce J.M. (2002): Human factors in the training of pilots. Taylor \& Francis, ISBN 0-203-16458-X, pp. 148-149

15. Wise J.A., Hopkin V.D., Garland D.J. (2010): Handbook of aviation human factors. Second edition, CRC Press Taylor \& Francis Group, ISBN 978-0-8058-5906-5, pp. 14-7, 14-10

16. Davis J.R., Johnson R., Stepanek J., Fogarty J.A. (2008): Fundamentals of aerospace medicine. Fourth edition, Lippincott Williams \& Wilkins, ISBN 978-0-7817-7466-6, p. 493

17. Seedhouse E., Brickhouse A., Szathmary K., Williams E.D. (2020): Human factors in air transport. Understanding behaviour and performance in aviation. Springer, ISBN 978-3-030-13847-9, pp. 100-103, 127-126

18. Salas E., Maurino D. (2010): Human Factors in aviation. Second edition, Academic Press Elsevier, ISBN 978-012-374518-7, pp. 202-203

19. Gibb R., Gray R., Scharff L. (2010): Aviation visual perception. Research, misperception and mishaps. Ashgate Publishing Limited, ISBN 978-0-7546-7497-9, p. 26

20. Trevor T. (2006): Human factors \& pilot performance. Air Pilot's Manual. Air Pilot Publishing, 3rd edition, ISBN 978-1843360704, pp. 104-105, https://www.amazon.co.uk/Human-Factors-Performance-Pilots-Manual/ dp/1843360705

21. Vidulich M.A., Tsang P.S., Flach J.M. (2014): Advances in aviation psychology. Vol. I, Ashgate Publishing Limited, ISBN 978-1-4724-3841-6, p. 58, p. 98

22. Salas E., Bowers C.A., Edens E. (2001): Improving teamwork in organizations: applications of resource management training. CRC Press Taylor \& Francis Group, pp. 13-15, https://doi.org/10.1201/b12465

23. Kanki B.G., Anca J., Chidester T.R. (2019): Crew Resourse Management. Third edition, Academic Press Elsevier, ISBN 978-0-12-812995-1, pp. 53-56, 103-105, 165-166, 385

24. Kirwan B., Wies M., Charles R., Dormoy C.-A., Letouze T., Lemkadden A, Maille N., Nixon J., Ruscio D., SchmidtMoll C. (2019): Charting the Edges of Human Performance. Les Ulis: EDP Sciences, http://dx.doi.org.am.enformation.ro/10.1051/matecconf/201930406007

25. Nixon J., Pilbeam C., Kirwan B. (2019): Pragmatic science? Reflections on the academic - industry interactions in a european aviation research programme. EDP Sciences, MATEC Web Conf., Vol. 304, http://dx.doi.org.am.enformation.ro/10.1051/matecconf/201930406003

26. Aricò P., Borghini G., Di Flumeri G., Colosimo A., Bonelli S., Golfetti A., Pozzi S., Paullmbert J., Granger G., Benhacene R., Babiloni F. (2016): Adaptive automation triggered by EEG-based mental workload index: A passive brain-computer interface application in realistic air traffic control environment. Frontiers in Human Neuroscience, eISSN 1662-5161, 10:539, https://doi.org/10.3389/fnhum.2016.00539

27. Nixon J., Charles R. (2017): Understanding the human performance envelope using electrophysiological measures from wearable technology. Cognition, Technology \& Work, ISSN 1435-5558, Vol. 19, pp. 655-666, https://doi.org/10.1007/s10111-017-0431-5

28. Edwards T., Homola J., Mercer J., Claudatos L. (2017): Multifactor interactions and the air traffic controller: The interaction of situation awareness and workload in association with automation. Cognition, Technology \& Work, ISSN 1435-5558, Vol. 19, is. 4pp. 687-698, https://doi.org/10.1007/s10111-017-0445-z

29. Biella M., Wies M. (2017): What the pilots see is what I get: how pilot's gaze can increase the Human Performance Envelope to improve safety. International Conference on Applied Human Factors and Ergonomics, Los Angeles, California, USA, https://elib.dlr.de/110069/ 